\title{
Role of Ultrasound and Magnetic Resonance Imaging in Evaluation of Elbow Pain
}

\author{
Reham Samy Sheta ${ }^{1, *}$, Rasha Lotfy Younis ${ }^{1}$, Radwa Mostafa Elkhouly ${ }^{2}$, Atef Hammad Teama ${ }^{1}$ \\ ${ }^{1}$ Department of Radiology, Faculty of Medicine, Tanta University, Tanta, Egypt \\ ${ }^{2}$ Department of Rheumatology, Physical Medicine \& Rehabilitation, Faculty of Medicine, Tanta University, Tanta, Egypt
}

\section{Email address:}

rsheta80@gmail.com (R. S. Sheta), rasha.younis@med.tanta.edu.eg (R. L. Younis), radwa.elkhouli@med.tanta.edu.eg (R. M. Elkhouly), atef.toeama@med.tanta.edu.eg (A. H. Teama)

${ }^{*}$ Corresponding author

\section{To cite this article:}

Reham Samy Sheta, Rasha Lotfy Younis, Radwa Mostafa Elkhouly, Atef Hammad Teama. Role of Ultrasound and Magnetic Resonance Imaging in Evaluation of Elbow Pain. International Journal of Medical Imaging. Vol. 8, No. 4, 2020, pp. 114-125.

doi: $10.11648 /$ j.ijmi.20200804.18

Received: November 23, 2020; Accepted: December 4, 2020; Published: December 11, 2020

\begin{abstract}
The elbow is a complex joint designed to withstand a wide range of dynamic exertional forces. There are multiple lesions causing pain at the elbow. The location and quality of elbow pain can generally localize the injury to one of the four anatomic regions: anterior, medial, lateral, or posterior elbow. The purpose of this study is to evaluate the role of ultrasound and magnetic resonance imaging in identifying elbow pain causes. Sixty patients (36male and 24 female) were enrolled in this study who are complaining from elbow pain and or any discomfort at elbow region. Tendinous elbow lesions (flexor and extensor tendon injury) were the most detectable lesions (50/172) (29.0\%), followed by ligamentous lesions (medial and lateral collateral ligament injuries) (42/172) (24.41\%), bony lesions (38/172) $(22.09 \%)$, muscle lesions $(24 / 172)(13.95 \%)$ and nerve lesions come last with (20/172) (11.76\%). Ultrasound is a rapid cheap modality of choice regarding screening of elbow tendionous and ligamentous injury to lesser degree bony and neural lesions, MRI should be considered to assess precisely the extent of any injury in addition to the value of bone visualization \& nerve evaluation. Magnetic resonance neurography is a potentially useful diagnostic tool in the evaluation of ulnar neuropathy at the elbow especially ulnar nerve.
\end{abstract}

Keywords: Ultrasound, Magnetic Resonance Imaging, Ulnar Nerve Neurography

\section{Introduction}

The musculoskeletal system can be subjected to acute injuries including contusions, strains, sprains, tearing of soft tissues, dislocations, fractures or any combination of these. Systemic diseases including rheumatologic, endocrine, and vascular can lead also to alteration of musculoskeletal biomechanics, which ultimately can change one's function. Infection, tumors are other conditions that can lead to the musculo-skeletal morbidity of varied severity [1].

The elbow is a complex joint designed to withstand a wide range of dynamic exertional forces. The location and quality of elbow pain can generally localize the injury to one of the four anatomic regions: anterior, medial, lateral, or posterior [2].

Ultrasonography has several advantages over other imaging techniques, importantly because of dynamic examination in addition to its rapid, cheap and focused criteria [3].

US may be successfully used to show joint effusion, analyze the features of synovtis in inflammatory diseases, assess tendon, bursae, ligaments nerves and entheseal involvement in patients with pain and swelling of elbow. [4]

With its high spatial resolution, excellent soft tissue contrast, and multiplanar imaging capabilities, MRI is often the imaging modality of choice for the evaluation of the painful elbow. The introduction of high-field scanners have reduced scan times and cost with improved image resolution. [5]

MRI has become the procedure of choice for evaluating elbow abnormalities, providing images of injuries to ligaments and tendons, compressive or entrapment neuropathy, bone injuries, inflammatory and synovial conditions, as well as soft-tissue masses. [6] 
Magnetic resonance neurography (MRN) is an imaging study designed to examine peripheral nerves, MRN allows both direct assessment of the nerve lesion, as well as indirect signs of nerve injury such as associated regional muscle denervation. MRN provides better anatomic localization of the entrapment site than is possible with EMG studies, as well as information on the nature of the underlying causative lesion (e.g., benign or malignant mass, fibrosis). [7]

\section{Patients Methods}

60 patients complaining from elbow pain enrolled in this study. They were referred to Radio-diagnosis \& Medical Imaging Department from clinics of Orthopedic and Physical Medicine Departments for Ultrasound \& MRI evaluation \& assessment. Informed written consent were obtained from all participants in the study after full explanation of the benefits and risks of the procedure. Privacy \& confidentiality of all patient data were guaranteed. All data provision were monitored and used for scientific purpose only.

\subsection{Inclusion Criteria}

Patients with elbow pain and /or any discomfort and swelling at elbow region, they were clinically fit to participate in the study and they have no contraindication to MRI.
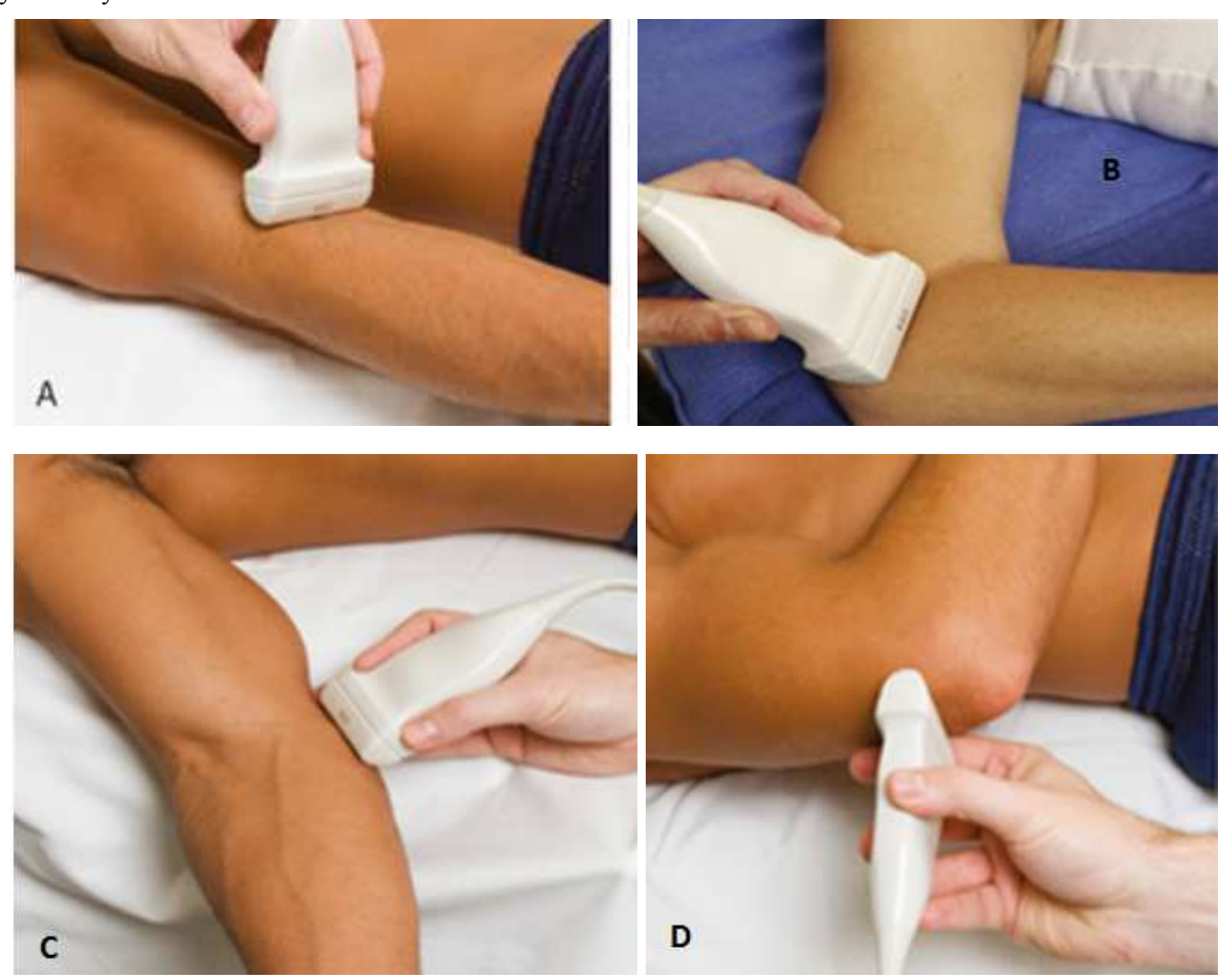

Figure 1. (A) anterior elbow (B) lateral elbow (c) medial elbow (D) posterior elbow. ${ }^{(8)}$

\subsection{Exclusion Criteria}

Patients with recent trauma with fracture or recent opened wound.

\subsection{Methods}

\subsubsection{Full History Taking}

Present history of Elbow pain, time of occurrence and relation to efforts. Other symptoms as tingling, numbness, swelling and limitation of movement.

\subsubsection{Clinical Examination}

Including general examination and local elbow examination. The local elbow examinations were done by single independent orthopaedic surgeon and rheumatologist.

Ultrasound is done followed by MRI examination.

\subsubsection{Ultrasound Examination}

Ultrasound examination of the elbow was done using highfrequency linear transducers with frequencies ranging from 10 to $18 \mathrm{MHz}$ with the use of Color and power Doppler imaging.

A complete assessment of the elbow was in transverse and longitudinal images of all four aspects of the joint: Anterior, lateral, medial, and posterior lateral (figure 1). 


\subsubsection{MRI Examination}

MRI studies were obtained using a closed MRI machine 1.5-T MRI system

Patients were in supine position with the arm at the side and palm up.

\subsubsection{The MRI Scanning Protocol Included the Following}

1. Scout 3 planes T1 weighted images (T1WI) were taken for localization of the subsequent slices.

2. Axial $\mathrm{T} 1$ weighted images $(\mathrm{TR} / \mathrm{TE}=600-800 / 15-30)$ and axial $\mathrm{T} 2$ weighted images $(\mathrm{TR} / \mathrm{TE}=2000-5000 / 60$ 120).

3. Sagittal $\mathrm{T} 1, \mathrm{~T} 2$ and gradient weighted images $(\mathrm{TR} / \mathrm{TE}=$ $500-600 / 12-20)$.

4. Coronal STIR (short time inversion recovery) (TR/TE= 4000-6000/20-40) coronal T1 and T2 weighted images.

5. Post contrast T1 WI studies in 18 patients after using IV injection of $0.1 \mathrm{mmol} / \mathrm{kg}$ of Gd-DTPA (Gadolinium diethylene triamine penta acetic acid) (Magnivest) in these patients followed by $5 \mathrm{ml}$ saline injection, imaging followed injection within half an hour.

6. Magnetic resonance neurography (MRN) short time inversion recovery (STIR) imaging \& Fast Imaging Employing Steady-state Acquisition (FIESTA)

7. With field of view (FOV) ranging between 12 to $16 \mathrm{~cm}$ with matrix size $256 \times 256$, slice thickness was about 2 to $4 \mathrm{~mm}$ with inter-slice gap of about 0.2 to $0.5 \mathrm{~mm}$.

\subsubsection{Image Analysis}

The findings obtained for each patient were analyzed and compared with serology, operative data \& histopathology which were considered the gold standard for our study.

\section{Results}

This prospective study included 60 (36 male, 24 female). Their age ranged from 20 to 60 years $\&$ mean age $40.03 \pm 6.84$. (Table 1), Representing the demographic data of the patients.

The findings were divided according to tissue involved into tendinous lesions followed by ligamentous lesions, bony lesions, muscle lesions and lastly nerve lesions.

N. B. More than one MR. finding was detected in the same patient (Overlapping).

Regarding various elbow lesions, tendenous injury was the most common elbow lesion in this study (50/172)(29.0\%). In which lateral epicondylitis tendinopathy was more common $(34 / 50)(68 \%)$ than medial epicondylitis tendinopathy $(16 / 50)$ $(32 \%)$. ligamentous injury followed tendionus lesions whereas, medial collateral ligament injury was more common $(28 / 42)(66.6 \%)$ than the lateral collateral ligament injury (14/42) (33.3\%). Regarding osseous lesions, which represented (38/172) $(22.09 \%)$, bony erosions was the most common $(16 / 36)(44.4 \%)$, followed by osteophytes $(10 / 36)$ (27.7\%), bony masses (8/36) $12.8 \%$; four of them are osteochondromas, the other four are giant cell tumors. Lastly two cases of osteochondritis desiccant. For ulnar nerve lesions we detected 20 cases of ulnar nerve neuropathy in which altered ulnar nerve signal represented $(10 / 20)$ $(50.0 \%)$, thickened ulnar nerve detected in $(6 / 20)(30 \%)$ while, both pathologies seen in (4/20) (20).

Table 1. Showing the demographic data of all patients (60 cases):

\begin{tabular}{|c|c|c|c|c|}
\hline \multirow{2}{*}{$\begin{array}{l}\text { Characteristics } \\
\text { Age group }\end{array}$} & \multicolumn{2}{|l|}{ Sex } & \multirow{2}{*}{ Total } & \multirow{2}{*}{ Ratio (\%) } \\
\hline & Male & Female & & \\
\hline $20-<30$ & 4 & 0 & 4 & $6.66 \%$ \\
\hline $30-<40$ & 14 & 10 & 24 & $40.0 \%$ \\
\hline $40-<50$ & 12 & 8 & 20 & $33.33 \%$ \\
\hline $50-<60$ & 6 & 6 & 12 & $20.0 \%$ \\
\hline Total No. & 36 & 24 & 60 & $100 \%$ \\
\hline Min. - Max. & \multicolumn{4}{|c|}{$20-60$} \\
\hline Mean \pm SD & \multicolumn{4}{|c|}{$40.03 \pm 6.84$} \\
\hline
\end{tabular}

Table 2. Showing different lesions in our study according to tissue involvement.

\begin{tabular}{|c|c|c|c|c|c|c|}
\hline \multirow{3}{*}{ Tendon lesion (50) } & \multicolumn{6}{|l|}{ MRI Findings } \\
\hline & \multicolumn{2}{|l|}{ Tendinosis } & \multicolumn{2}{|l|}{ Partial tendon tear } & \multicolumn{2}{|l|}{ complete tendon tear } \\
\hline & Findings & N.\&\% & Findings & N. $\& \%$ & Findings & N. \&\% \\
\hline $\begin{array}{l}\text { Medial Epicondylitis } \\
\text { (16): }\end{array}$ & $\begin{array}{l}\text { Thickening of the affected } \\
\text { tendons, with areas of } \\
\text { intermediate signal intensity on } \\
\text { both T1- and T2WI }\end{array}$ & $8(50 \%)$ & $\begin{array}{l}\text { showed increased T2 } \\
\text { signal within or } \\
\text { surrounding tendon }\end{array}$ & $6(37.5 \%)$ & $\begin{array}{l}\text { Complete disruption } \\
\text { of the tendon \& } \\
\text { increased T2 signal } \\
\text { fluid in a tendon gap }\end{array}$ & $2(12.5 \%)$ \\
\hline
\end{tabular}




\begin{tabular}{|c|c|c|c|c|c|c|}
\hline \multirow{3}{*}{$\begin{array}{l}\text { Ligamentous } \\
\text { lesion (42) }\end{array}$} & \multicolumn{6}{|l|}{ MRI Findings } \\
\hline & \multicolumn{2}{|l|}{ Grade I } & \multicolumn{2}{|l|}{ Grade II } & \multicolumn{2}{|l|}{ Grade III } \\
\hline & Findings & N. \& $\%$ & Findings & N. \&\% & Findings & N. \& \% \\
\hline $\begin{array}{l}\text { Medial } \\
\text { Collateral } \\
\text { ligament injury } \\
(28)\end{array}$ & $\begin{array}{l}\text { Alterations in morphology } \\
\text { either (thinning or } \\
\text { thickening) or high SI on } \\
\text { T1WI or T2WI. }\end{array}$ & $18(64.2 \%)$ & $\begin{array}{l}\text { Areas of intra-substance } \\
\text { low fluid signal (T1WI } \\
\text { SI, high T2WI SI) with } \\
\text { focal disruption of } \\
\text { ligamentous fibers }\end{array}$ & $6(21.4 \%)$ & $\begin{array}{l}\text { Fluid signal } \\
\text { intensity gap (low } \\
\text { T1WI\&high T2WI) } \\
\text { between disrupted } \\
\text { fibers }\end{array}$ & $4(14.2 \%)$ \\
\hline $\begin{array}{l}\text { Lateral } \\
\text { Collateral } \\
\text { ligament injury } \\
\text { (14) }\end{array}$ & $\begin{array}{l}\text { Alterations in morphology } \\
\text { either (thinning or } \\
\text { thickening) or high SI on } \\
\text { T1WI or T2WI. }\end{array}$ & $8(57.1 \%)$ & $\begin{array}{l}\text { Areas of intra-substance } \\
\text { low fluid signal (T1WI, } \\
\text { high T2WI SI) with focal } \\
\text { disruption of } \\
\text { ligamentous fibers }\end{array}$ & $4(28.5 \%)$ & $\begin{array}{l}\text { Fluid signal } \\
\text { intensity gap (low } \\
\text { T1WI\&high T2WI) } \\
\text { between disrupted } \\
\text { fibers }\end{array}$ & $2(14.2 \%)$ \\
\hline
\end{tabular}

\begin{tabular}{|c|c|c|c|c|}
\hline Bone lesion (36) & MRI findings & N.\&\% & US findings & N.\&\% \\
\hline Erosions & Breaks in the cortical bone surface & $16(44.4 \%)$ & $\begin{array}{l}\text { Breaks in the cortical } \\
\text { bone surface }\end{array}$ & $6(16.6 \%)$ \\
\hline Osteophytes & $\begin{array}{l}\text { Appeared as bony proliferations (spurs) with same } \\
\text { signal as bone itself. }\end{array}$ & $10(27.7 \%)$ & $\begin{array}{l}\text { bony proliferations } \\
\text { (spurs) continuous with } \\
\text { bone. }\end{array}$ & $4(11.1 \%)$ \\
\hline Giant cell tumor & $\begin{array}{l}\text { Expansible bony mass arising from lower medial } \\
\text { aspect of humerus with low signal at T1WI\& } \\
\text { intermediate at T2WI\&PD FAT SAT with } \\
\text { heterogeneous enchantment }\end{array}$ & $4(11.1 \%)$ & $\begin{array}{l}\text { Disfiguring mass } \\
\text { continuous with bone } \\
\text { arising from distal medial } \\
\text { aspect of humerus }\end{array}$ & $2(5.5 \%)$ \\
\hline Osteochondroma & $\begin{array}{l}\text { Sessile mass seen in upper lateral aspect radius, } \\
\text { covered by cap of cartilage displaying intermediate } \\
\text { signal on } \mathrm{T} 1 \text { and high signal on } \mathrm{T} 2 \mathrm{WI}\end{array}$ & $4(11.1 \%)$ & $\begin{array}{l}\text { Bony mass arising from } \\
\text { proximal lateral aspect } \\
\text { radius covered with } \\
\text { hypoechoic region }\end{array}$ & $2(5.5 \%)$ \\
\hline $\begin{array}{l}\text { Osteochondritis desiccant } \\
\text { grade IV }\end{array}$ & $\begin{array}{l}\text { A small separated bone fragment is seen arising from } \\
\text { intra-articular surface of capitulum with fluid seen } \\
\text { interposed between it and parent bone \& fluid-filled } \\
\text { cysts beneath the lesion. }\end{array}$ & $2(5.5 \%)$ & $\begin{array}{l}\text { Discontinuity of } \\
\text { subchondral bony part of } \\
\text { capitulum of humerus. }\end{array}$ & $2(5.5 \%)$ \\
\hline
\end{tabular}

\begin{tabular}{|c|c|c|c|c|}
\hline \multirow{2}{*}{$\begin{array}{l}\text { Muscle lesions } \\
\text { (32) }\end{array}$} & \multicolumn{2}{|l|}{ MRI Findings } & \multicolumn{2}{|l|}{ US Findings } \\
\hline & Findings & N. \&\% & Findings & N. \&\% \\
\hline Myositis & $\begin{array}{l}\text { High T2WI signal intensity in muscle with normal } \\
\text { anatomic architecture }\end{array}$ & $16(50 \%)$ & $\begin{array}{l}\text { Swollen heterogeneous muscle with } \\
\text { increased color flow on color Doppler study }\end{array}$ & $10(31.2 \%)$ \\
\hline Hematoma & $\begin{array}{l}\text { Oblong shape swelling of brachialis muscle seen } \\
\text { displaying low signal intensity at T1WI, high T2WI } \\
\text { signal intensity and FAT SAT signal intensity.(subacute) }\end{array}$ & $6(18.7 \%)$ & $\begin{array}{l}\text { well - defined heterogeneously echoic mass } \\
\text { inside brachialis muscle with no color flow } \\
\text { on color Doppler study. }\end{array}$ & $4(12.5 \%)$ \\
\hline $\begin{array}{l}\text { Intra-muscular } \\
\text { collection }\end{array}$ & $\begin{array}{l}\text { Well defined cystic lesion seen inside triceps muscle } \\
\text { displaying low signal at T1WI, high SI at T2WI with } \\
\text { marginal enhancement. }\end{array}$ & $4(12.5 \%)$ & $\begin{array}{l}\text { Well defined heterogeneous fluid collection } \\
\text { seen inside triceps muscle with internal } \\
\text { debris. }\end{array}$ & $4(12.5 \%)$ \\
\hline $\begin{array}{l}\text { Muscular soft } \\
\text { tissue sarcoma }\end{array}$ & $\begin{array}{l}\text { Ill defined intra-muscular mass displaying low T1- } \\
\text { Ssignal intensity and high T2WI SI with variable } \\
\text { contrast enhancement. Foci of necrosis seen within. }\end{array}$ & $4(12.5 \%)$ & $\begin{array}{l}\text { Ill defined intra-muscular mass with low to } \\
\text { intermediate echogenicity. marked } \\
\text { vascularity noted on color Doppler imaging. }\end{array}$ & $4(12.5 \%)$ \\
\hline $\begin{array}{l}\text { Myositis } \\
\text { ossificans }\end{array}$ & $\begin{array}{l}\text { Well defined lobulated mass lesion seen at the left } \\
\text { postero-medial aspect of the elbow joint intra \&inter } \\
\text { muscular in location displaying low signal intnesity at } \\
\text { T1WI and high SI at T2WI, it shows mildly } \\
\text { heterogeneous enhancement. }\end{array}$ & $2(6.25 \%)$ & $\begin{array}{l}\text { Extensive shadowing \& calcification seen } \\
\text { inside brachialis muscle. }\end{array}$ & $2(6.25 \%)$ \\
\hline
\end{tabular}

\begin{tabular}{|c|c|c|c|c|}
\hline \multirow{2}{*}{$\begin{array}{l}\text { Ulnar nerve } \\
\text { affection (20) }\end{array}$} & \multicolumn{2}{|l|}{ MRI } & \multicolumn{2}{|l|}{ Ultrasound } \\
\hline & Findings & N.\&\% & Findings & N.\&\% \\
\hline Altered nerve signal & Abnormal nerve signal displaying high T2 WI \&, STIR SI. & $10(50.0 \%)$ & The ulnar nerve is seen hypoechoic & $6(50 \%)$ \\
\hline Thickened nerve & Increased nerve diameter, enlarged nerve. & $6(30 \%)$ & $\begin{array}{l}\text { The ulnar nerve is seen edematous } \\
\text { swollen }\end{array}$ & $\begin{array}{l}4 \\
(33.3 \%)\end{array}$ \\
\hline $\begin{array}{l}\text { Altered signal and } \\
\text { thickened nerve }\end{array}$ & $\begin{array}{l}\text { Abnormal nerve signal displaying high T2 WI \&, STIR SI \& } \\
\text { Increased nerve diameter, enlarged nerve. }\end{array}$ & $4(20 \%)$ & $\begin{array}{l}\text { The ulnar nerve is seen both } \\
\text { edematous, enlarged more } \\
\text { hypoechoic. }\end{array}$ & $\begin{array}{l}2 \\
(16.6 \%)\end{array}$ \\
\hline
\end{tabular}




\section{Cases}

\subsection{Case 1 Male Patient Aged 30 Years Old Presented by Severe Elbow Pain After Lifting of Heavy Object}
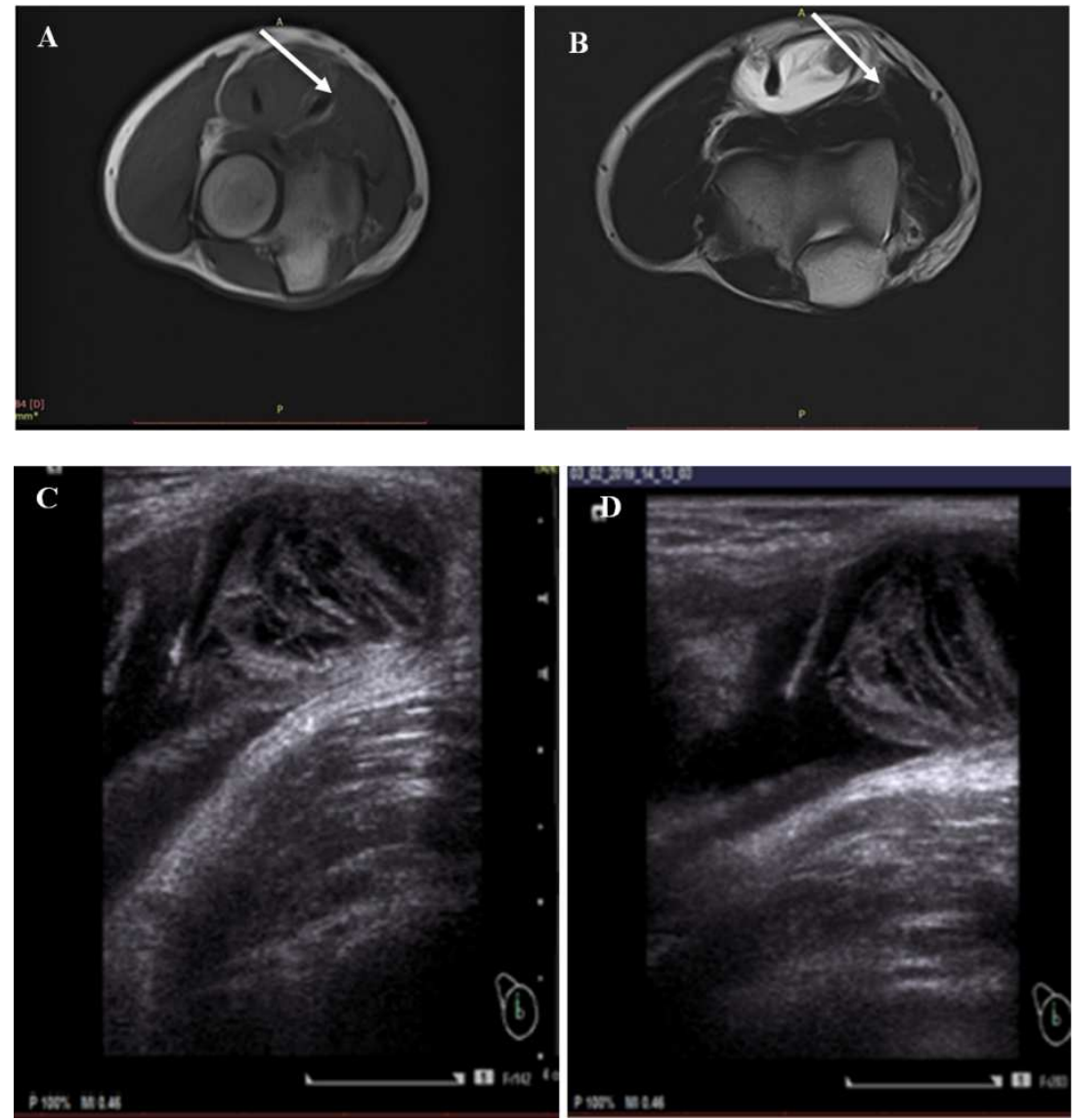

A case of intra-muscular hematoma proved by operative intervention

Figure 2. (A) Axial Figure 1 (A) T1WI,(B) axial T2WI at elbow joint, showing well defined cystic lesion seen inside biceps muscle displaying low signal at $T 1 W I$ (A) and high signal at T2WI denoting chronic stage hemorrhage (B), the lesion is seen insinuating between anterior elbow muscular compartment. On ultrasound images $(C \& D)$ showed relatively well - defined heterogeneously soft tissue mass like lesion seen inside biceps muscle with area of anechoic signal seen within this mass lesion with no color flow on color Doppler

\subsection{Case 2 A Female Patient Aged 50 Years old Presented by Right Elbow Pain, Swelling and Inability to Move the Elbow}

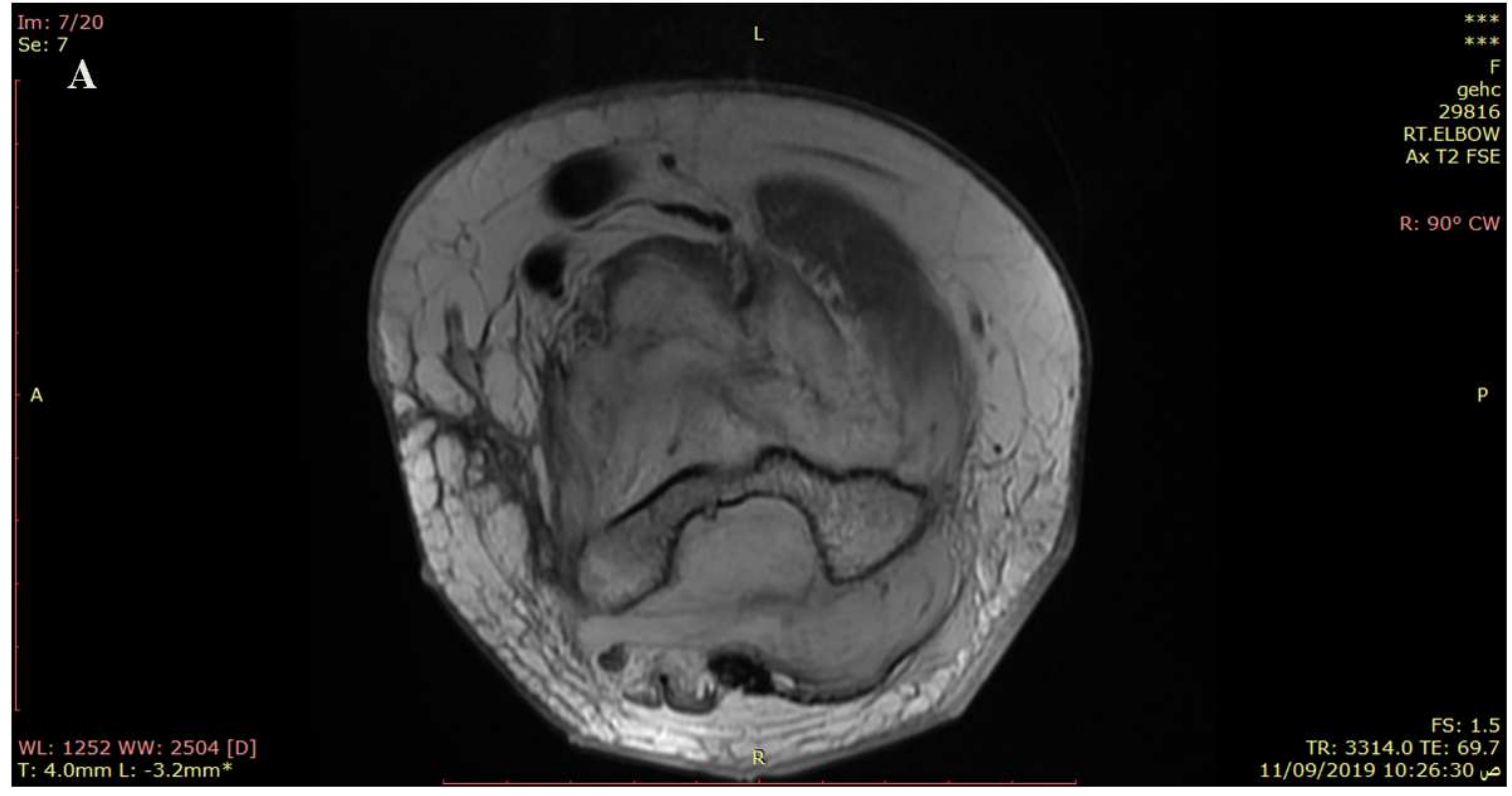



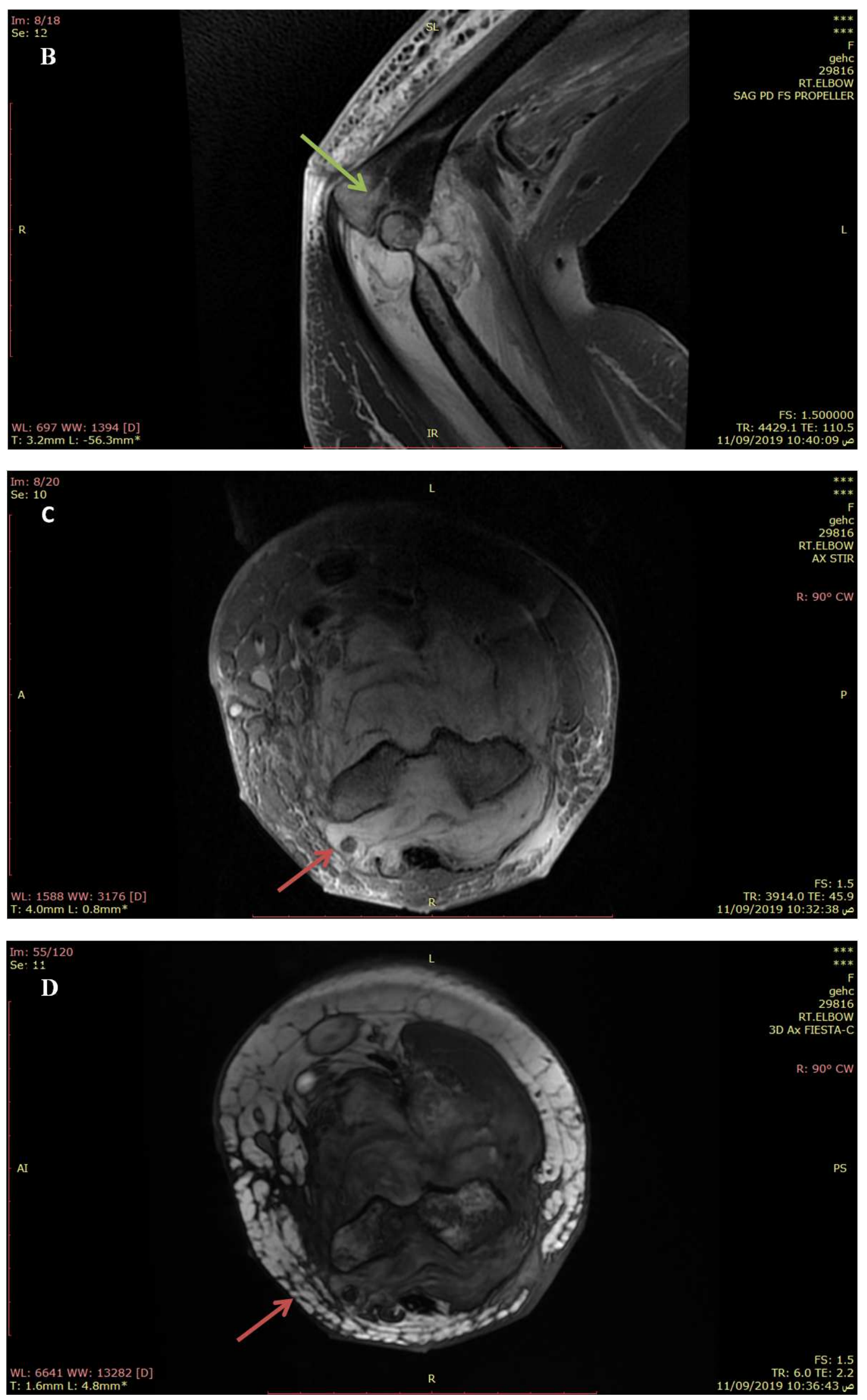

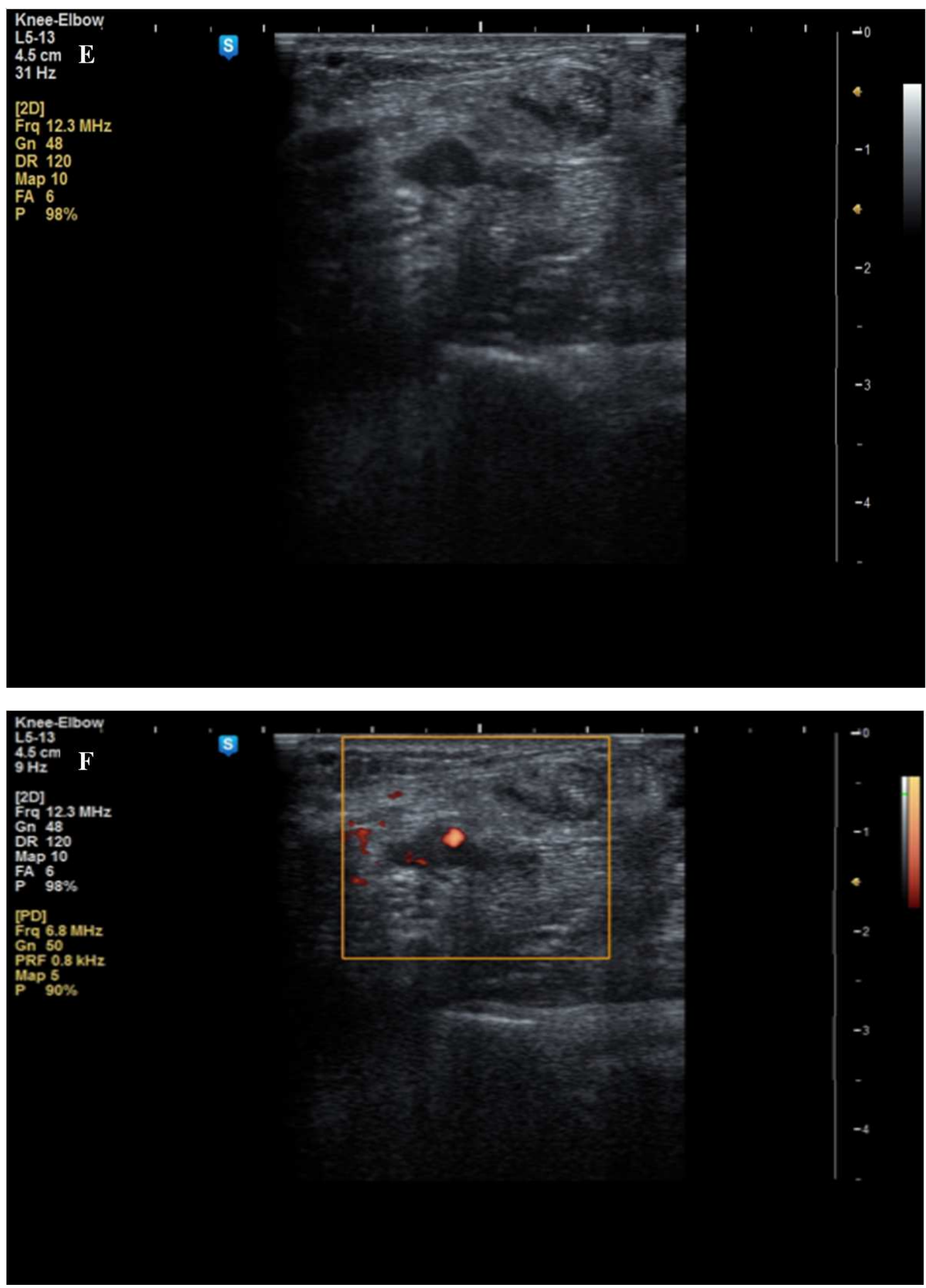

Figure 3. (A) Axial T2WI (B) sagittal PDFATSAT \& (c) Axial STIR (D) axial 3D FIESTA reveled marked edema affecting all muscles of elbow biceps, triceps and brachialis, subcutaneous tissue overlying the elbow (A), areas of increased bone marrow signal are seen denoting bone marrow edema (B) (green arrow) as an early sign of bony affection ulnar nerve is seen thickened with altered signal at both STIR \& FIESTA sequences (red arrow) (C\&D). On Real time ultrasound images of the same patient; transverse view at elbow region showed diffuse subcutaneous edema (E), on color Doppler study seen at (F) showed inflamed and swollen muscle with detected color flow inside muscles.

Over all picture is of elbow joint septic arthritis with ulnar nerve affection by inflammatory response. 


\subsection{Case 3 a Male Patient Aged 32 Years Old Complaining of Right Elbow Pain for 2 Months Mri Pictures}
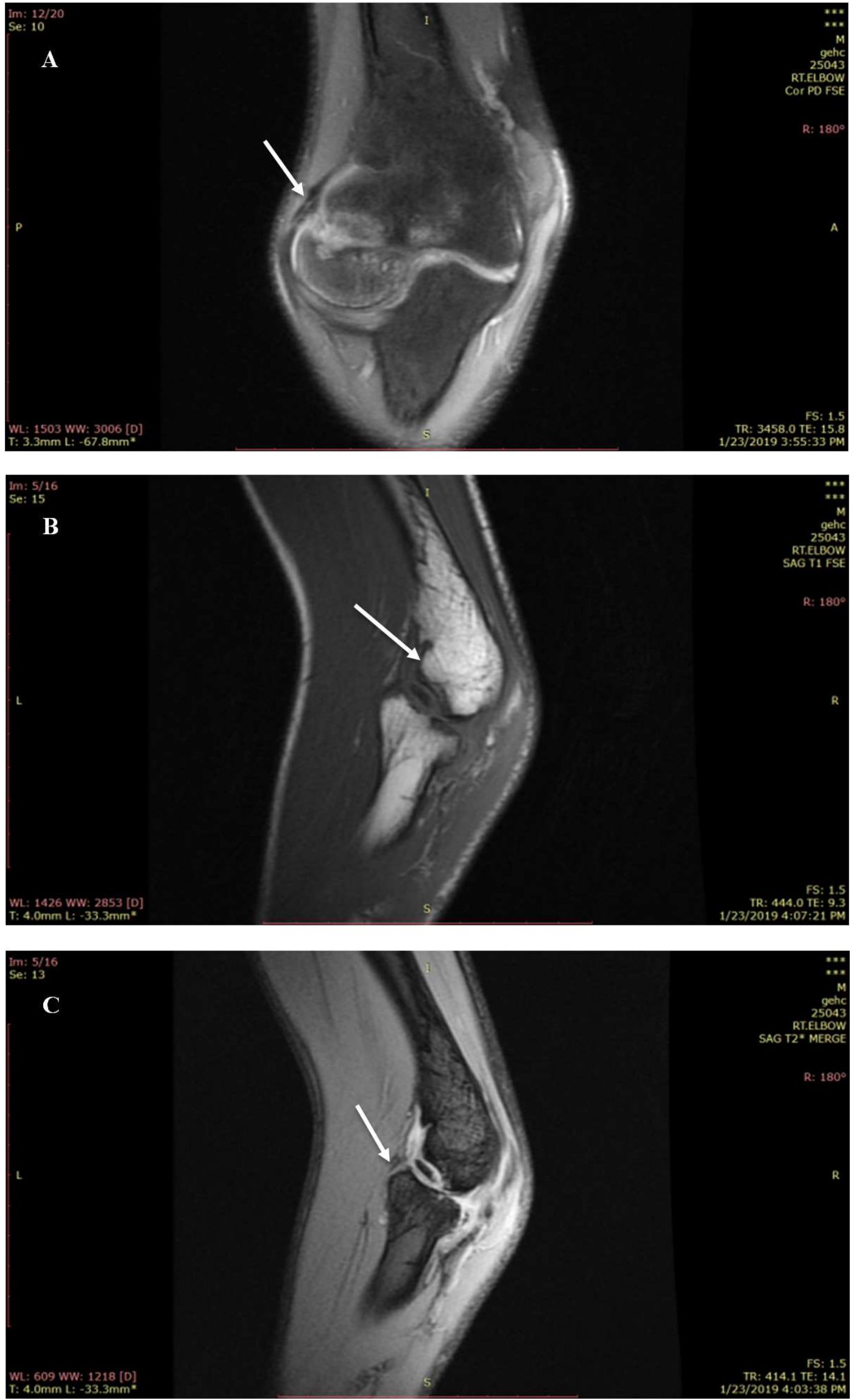

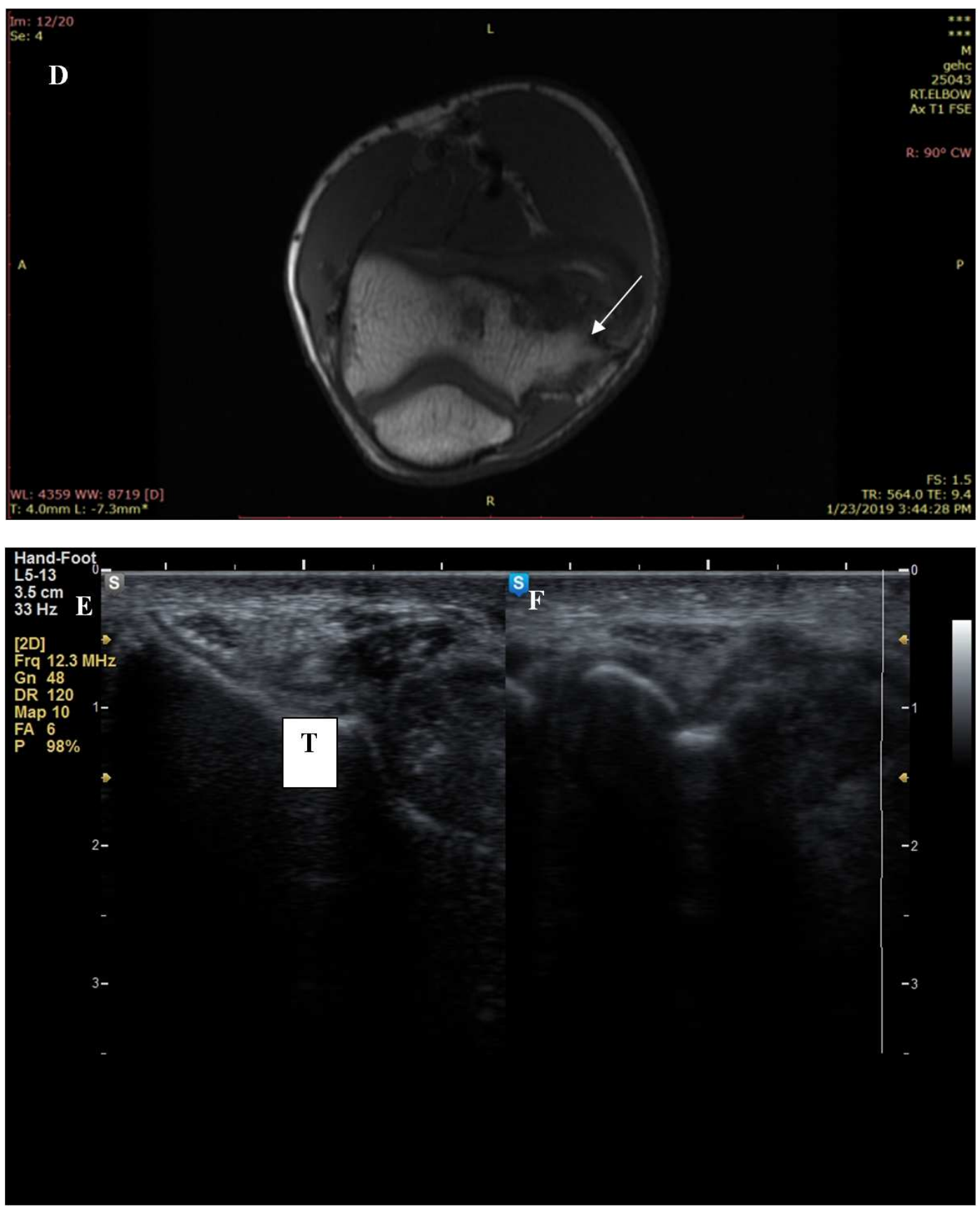

A case of capitulum osteochondritis dissecans (OCD) grade V.

Figure 4. (A) coronal PDFATSAT, B) sagittal T1WI, C) sagittal Gradient \& D) axial TIWI showed small separated bone fragment is seen arising from intraarticular surface of capitulum with fluid signal seen interposed between it and the parent $(C)$, the bony fragment is seen displaced, the opposing articular surface of radio-capitular joint showing bone marrow edema and fluid-filled cysts beneath the lesion $(A \& B)$ that is more evident at the radial surface, location of separated bone fragment anteriorly differentiae it from the normal variant capitular pseudo defect which is seen usually posteriorly. A note is done for elbow joint osteoarthritic changes in the form of marked narrowing of the joint space and loss of articular cartilage, irregular cortex and small osteophyte formation bone (D). Ultrasound showed discontinuity of subchondral bony part of capitulum of humerus (red arrow) (F), while in image E it showed normal continuity of lower medial humeral surface T....... (Trochlea).

\subsection{Case 4}

A female patient aged 60 years presented with right elbow pain associated with limitation of movement of elbow especially extension, with history of intra-muscular (triceps) injection one month ago. 

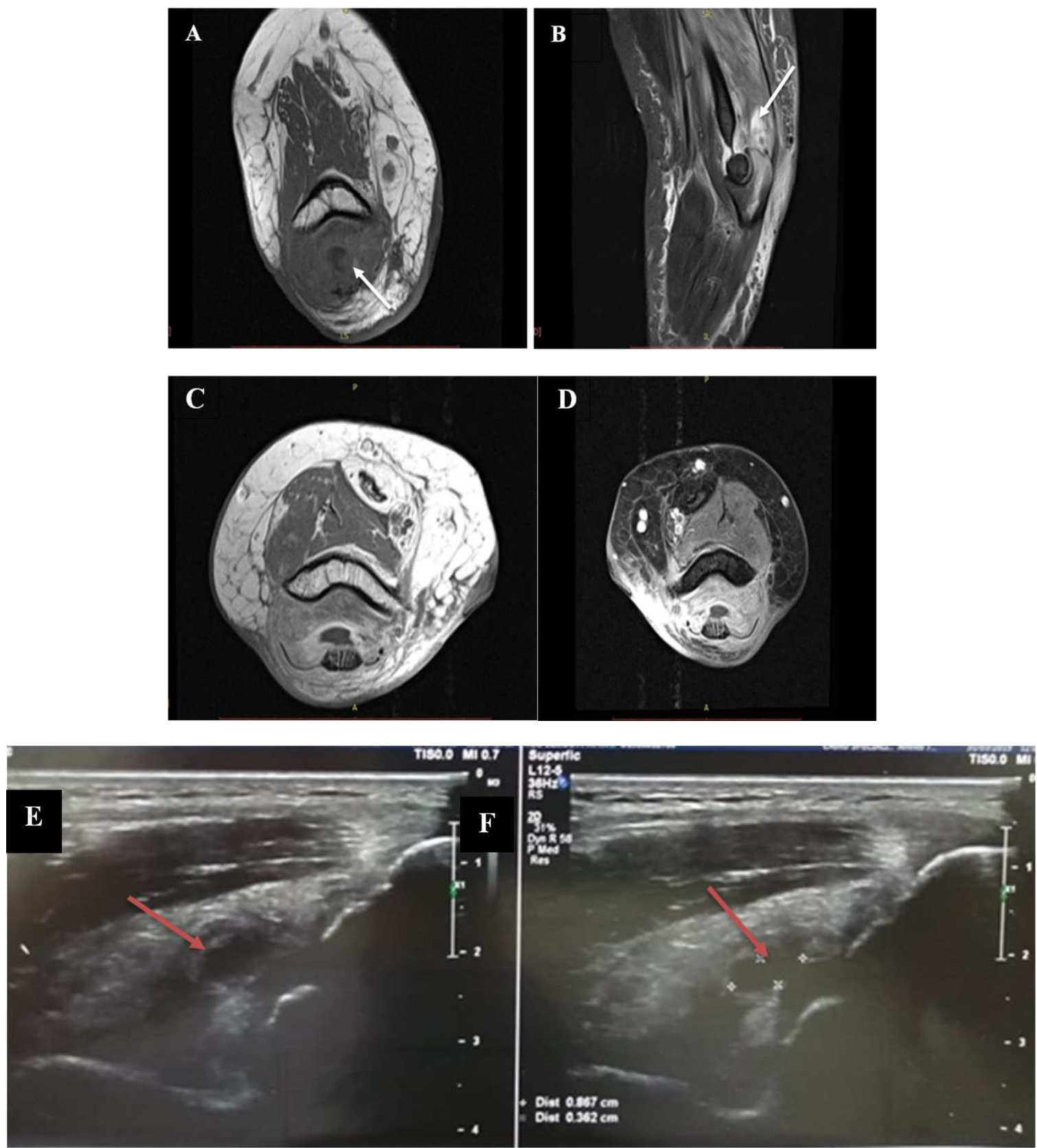

A case of triceps intramuscular collection.

Figure 5. (A) Axial TIWI (B) sagittal T2WI STIR, (C) axial TIWI at the same level \&(D) axial T2 STIR with contrast, well defined fluid collection seen inside the muscle fibers of triceps displaying low signal at $T 1 W I(A) \&(C)$, the lesion become more evident after contrast enhancement, as it showed marginal enhancement, high signal seen in bone marrow of distal humerus and olecranon process of ulna as well increased triceps muscle fibers signal at STIR sequence due to nearby inflammatory process $(B) \&(D)$. On ultrasound image (E\&F), showed well defined anechoic lesion measured about $5 \times 4 \mathrm{~mm}(\mathrm{red}$ arrow) seen inside the muscle fiber of triceps.

\section{Discussion}

The elbow is commonly affected by overuse disorders and inflammatory conditions. Various imaging techniques may be used to assess the elbow, including CT, MRI, and Ultrasound . Imaging plays a crucial role in the evaluation of elbow tendons, ligaments as well as bony lesions. [9]

Magnetic resonance imaging has been proven to provide excellent evaluation of ligaments and tendons around the elbow joint, with the ability to show various types of soft tissue and bony abnormalities. [10]

This study included sixty patients;(36 Male \& 24 Female) with elbow joint lesions of variable causes, In the study males represented $(60 \%)$ of all patients while female represented (40\%), with their age ranged from 20-60 years with mean age about $40 \pm 6.84$, the right side was more affected than the left side, as right sided affection was $66.7 \%$ of the total cases, while left side represented $33.3 \%$., this agreed with Hasan et al. [11] whose study was performed on 
36 patients, with male representing $52.7 \%$ and females representing $47.2 \%$ ranging in age from 20 to 64 years (mean age, 31 years), right side was affected by $(61 \%)$, and the left side $(39 \%)$.

In this study common extensor origin injury (lateral epicondylitis) was more common than common flexor tendon (medial epicondylitis) with $66.6 \%$ to $32 \%$ of total tendinosis lesions, this agreed with Shiri, R, et al [12] which was a random study on 4.783 population in which lateral epicondylitis represented $61 \%$ and medial epicondylitis represented $39 \%$ of these population.

In this study, lateral tendinopathy included three grades regarding degree of tendon injury, we detected 16 cases $(47.0 \%)$ with grade1 (Tendinosis) being the most common type of tendinous injury, 10 cases $(29.2 \%)$ grade II injury (Partial tear) \& 8 cases $(23.5 \%)$ grade III complete tear, this agreed with Zhang et al. [13] who stated that grades of lateral tendinopathy are also 3 grades $\&$ grade $\mathrm{I}$ is the most common type of injury with 38 cases $(39.6 \%), 31$ cases $(32.3 \%)$ with grade 2 , and 27 cases $(28.1 \%)$ grade 3 .

Regarding to ligamentous injury, medial collateral ligament injury was more affected (28/42) 66.6\% than lateral collateral ligament injury (14/42) $(33.3 \%)$, this agreed with Sarath Bethapudi et al. [14], in which medial collateral ligament injury was the most common ligament to be injured in the study group.

In this study there was a great association between lateral epicondylitis and lateral collateral ligament injury which agreed with Liang Qi et al.[15] in which lateral epicondylitis was mostly associated with other abnormalities, mostly RUCL injury.

Regarding to grades of injury of medial collateral ligament, grade I injury was the most common type of medial collateral ligament injury with 18 cases $(64.2 \%)$ of total ligamentous injury, grade II injury come second with 6 cases $(21.4 \%) . \&$ at last grade III injury with 4 cases $(14.2 \%)$ of total ligamentous injury, this disagreed with Gregory M. Ford, et al. [16] in which grade II was the most common type of elbow injury with $40 \%$, followed by grade III \& Last grade I

Ultrasound examination revealed 18 cases out of 28 cases $(64.2 \%)$ regarding medial collateral injury cases, while it revealed 12 out of 14 cases $(85 \%)$ of lateral collateral ligament injury this mismatched with Torquato Brandão, et al [17] who stated that ultrasonography and magnetic resonance imaging can be considered to some extend equivalent modalities for elbow ligament assessment in the hands of experienced examiners

In this study two cases of capitular osteochondritis desiccant is seen as a cause of elbow pain, OCD is a disorder of articular cartilage and subchondral bone which is classified into five grades, this case was grade $\mathrm{V}$ in which there was a displaced bone fragment and fluid signal seen interposed between it and the parent bone (Capitulum) as well as secondary degenerative changes, its location is in capitulum of humerus agreed with Christiaan J A van Bergen., et al [18] which stated that OCD of the elbow typically affects the humeral capitellum and leads to pain on the lateral aspect of the joint.

Regarding elbow joint bony neoplasm, this study included 10 neoplastic cases which represented $16 \%$ of total cases, four patients were diagnosed with giant cell tumor seen at lower humus, the other four patients were diagnosed with osteochondroma and seen at upper radius, this agreed with Halai, et al [19] which reported that primary bony tumors of the elbow are uncommon and account for approximately $1 \%$ of all osseous tumors encountered in study group.

Regarding ulnar nerve affection, using MR neurography (STIR \&FEISTA sequences) in tracing ulnar nerve at elbow region, thickened ulnar nerve detected at 10 cases $(50.0 \%)$ of total ulna nerve lesions, altered ulnar nerve signal 6 cases (30\%) \& 4 cases $(20 \%)$ have both pathologies this come along with Keen, N. [20] who stated that out of 21 patients with ulnar neuropathy, nineteen of patients qualitatively increased ulnar nerve size. Seventeen of them had qualitatively increased signal intensity of the ulnar nerve.

In this study using (MRN) in tracing ulnar nerve at elbow region we had the ability to detect 20 cases of ulnar nerve affection with different nerve lesions, on the other hand usual MRI had the ability to verify only 15 cases out of these 20 cases, with MRI sensitivity of $75 \%$ to $100 \%$ MRN sensitivity, this matched with Daniel Schwarz, et al [21] who stated that MRI sensitivity to nerve affection at cervical radiculopathy was $69 \%$ to $96 \%$ regarding MRN.

\section{Conclusion}

Us is a rapid cheap modality of choice regarding the elbow examination with precise examination of ligamentous injury $\&$ effusion, to less extend the rest of elbow lesions but can be used as a screening tool.

MRI revealed higher sensitivity relative to ultrasound results regarding the tendon lesions \& ligamentous injury.

Cases of bony lesions could be assessed accurately by MRI examination however; ultrasonography was much less sensitive than MRI in assessing these lesions.

Regarding intra-articular lesions (joint effusion \& synovial thickening) both MRI \&Ultrasound revealed nearly the same results with higher sensitivity of MRI over ultrasound.

Ulnar nerve lesions was better assessed by MRI especially MRN neurography sequences (FEISTA \& STIR) detecting its abnormal signal or fibers enlargement.

\section{Abbreviations}

MRI=Magnetic resonance imaging, US=Ultrasound, $\mathrm{MRN}=$ Magnetic resonance, neurography, $\mathrm{OCD}=$ osteochondritis dissecans.

\section{References}

[1] Sharma UK and Shrestha D. Musculoskeletal ultrasound: Is it ?underutilized in Kathmandu University Medical Journal, (2007).5 (4): 552-556. 
[2] Physicians, Am Fam Physician. Evaluation of Elbow Pain in Adults American Academy of Family and , (2014) 89 (8): 649-657.

[3] Avc1 M, Kozacı N, Beydilli, et al. The comparison of bedside point-of-care ultrasound and computed tomography in elbow injuries. The American Journal of Emergency Medicine, (2016). 34 (11), 2186-2190.

[4] A. Delle Sedie1, L. Riente1, A. ,Iagnocco et al, sound imaging for the rheumatologist VI. Ultrasonography of the ,elbow sacroiliac, parasternal, and temporomandibular joints, clinical and experimental rheumatology, (2006) (24), 617-621.

[5] Hauptfleisch J, English C \& Murphy D. Elbow Magnetic Resonance Imaging. Topics in Magnetic Resonance Imaging (2015,(24.(93-107).

[6] Melloni P\& Valls R. The use of MRI scanning for investigating of tissue abnormalities in the elbow. European Journal of Radiology, (2005). (10), 303-313.

[7] Machado, Chhabra, A. , Thawait, et al .High resolution imaging of tunnels by magnetic resonance neurography. Skeletal Radiology, (2011); 15-31. Jacobson, Jon A. Fundamentals of Musculoskeletal Ultrasound, chapter 4 Elbow Ultrasound, Jon A. Jacobson MD Third Edition, Elsevier. 2018; 127-167.

[8] Elisabetta Antonia Nocerino, Davide ,Cucchi Paolo Arrigoni, et al. Acute and overuse elbow trauma: radioorthopedics ,overview Acta Biomed. 2018 and 124-137., 89.

[9] Stein, J. M., Cook, T. S., Simonson, \& et .al Normal and Variant Anatomy of the Elbow on Magnetic Resonance Imaging. Magnetic Resonance Imaging Clinics of North America, (2011) and 609-619, (10).

[10] Hasan, N. M. A., Alam-Eldean, et al, Stiff elbow in adult. MR imaging .findings The Egyptian Journal of Radiology and Nuclear Medicine, 2015. 46 (4), 1037-1048.

[11] Shiri, Viikari-Juntura, Varonen, H., et .al Prevalence and Determinants of Lateral and Medial Epicondylitis: A Population .Study American Journal of Epidemiology, (2006) 164 (11), 1065-1074.
[12] Qi, L., Zhang, Y.-D., Yu, et al. Magnetic Resonance Imaging of Patients With Chronic Lateral Epicondylitis. Medicine, (2016) 95 (5)

[13] Sarath Bethapudi, Robinson, ,Engebretsen et al. Elbow Injuries at the London Summer Olympic Games: Demographics and Pictorial Imaging ,Review American Journal of Roentgenology (2013) and 201 (3), 535549.

[14] Liang Qi. , Zhu, \& Wang, R.-F. MR Imaging of Patients with Lateral Epicondylitis of the Elbow: Is the Common Extensor Tendon an Isolated Lesion? PLoS ONE, (2013); 8 (11).

[15] Gregory M. Ford, Genuario, ,Kinkartz et al. Return-to-Play Outcomes in Professional Baseball Players After Medial Ulnar Collateral Ligament Injuries. The American Journal of Sports Medicine, (2016). 44 (3), 723-728.

[16] Torquato Brandão, Aureliano, Amaro ,Junior Edson and Francisco Neto, et al Ultrasonography and magnetic resonance imaging of elbow ligaments: a comparative study, Einstein. 2019, Vol. 17 Issue 3, p1-6. 6p.

[17] Christiaan JA van Bergen, Kimberly IM van den Ende, Bart ten Brinke, et al, Osteochondritis dissecans of the capitellum in adolescents, world journal of .orthopedics 20167 (2): 102108.

[18] Halai, M., Gupta, S., et al A. Primary osseous tumors of the elbow: 60 years of rregistry experience. Shoulder \& Elbow, (2015) . 7 (4), 272-281.

[19] Keen, N. N., Chin, C. T., Engstrom, J. ,.W Saloner, D., \& Steinbach, L. S. Diagnosing ulnar neuropathy at the elbow using magnetic resonance neurography. Skeletal Radiology, (2011) and 41 (4), 401-407.

[20] Schwarz, D., Kele, H., Kronlage, M., ,Godel T., et al. Diagnostic Value of Magnetic Resonance Neurography in Cervical Radiculopathy. Investigative ,Radiology (2018). 53 (3), 158-166. 